\title{
Controlling the Building Model Using High Order Sliding Mode Control Optimized by Multi Objective Genetic Algorithm
}

\author{
Hasan Omur Ozer ${ }^{1}$, YukselHacioglu ${ }^{2}$, NurkanYagiz ${ }^{2}$ \\ ${ }^{1}$ Programme of Air Conditioning and Refrigeration Technology, Vocational School of Technical Science, Istanbul University \\ ${ }^{2}$ Department of Mechanical Engineering, Faculty of Engineering, Istanbul University
}

\begin{tabular}{l} 
Article Info \\
\hline Article history: \\
Received May $15^{\text {th }}, 2017$ \\
Revised Aug $18^{\text {th }}, 2017$ \\
Accepted Oct $18^{\text {th }}, 2017$ \\
\hline Keyword: \\
High Order Sliding Mode \\
Controller \\
Multi-Objective Genetic \\
Algorithm \\
Building Model \\
Active Tuned Mass Damper \\
Simulation
\end{tabular}

\section{Corresponding Author:}

Hasan Omur Ozer, Programme of Air Conditioning and Refrigeration Technology, Vocational School of Technical Science, Istanbul University 34320 Avcilar/ Istanbul, TURKEY.

Email: omurozer@istanbul.edu.tr

\section{Introduction}

External loads such as earthquakes have the potential to cause dangerous vibrations on buildings. Therefore, the need for studies on decreasing the effects of vibrations on buildings has increased during last decades and it is an important research area. Firstly, buildings have been protected by using the tuned mass damper (TMD) from hazardous effects of vibrations. The TMD, designed in 1909, is a passive control system consisting of mass, springs and viscous dampers. The optimum parameters of TMD for different systems are proposed by several researchers [1]-[2]-[3], a new approach for TMD is suggested by Villaverde [4-6], Sadek [7] improved study of Vilaverde. In order to control vibrations more effectively, numerous active control algorithms have been suggested. Pourzeynali et al. [8] have recommended that combining the GAs and fuzzy logic controller to obtain optimum values of ATMD is highly effective in decreasing seismically excited building vibrations. As a variable structure controller [9], Sliding mode control (SMC) is known to be a robust control method. In SMC, by changing control law according to certain predefined rules, the states are switched between stable and unstable trajectories until they reach the sliding surface [10]. When the system is on the sliding surface the closed-loop control system is insensitive to external disturbances and parameter variations. On the other hand, chattering may occur, that is high frequency oscillations may arise in control signal and states of the system. Therefore, high order sliding mode controller (HOSMC) method has been proposed in literature to prevent chattering $[11,12]$. In particular, The Super-Twisting Algorithm (STA) which is a well-known second order 
sliding mode (SOSM) algorithm is developed by Levant [12]. This control methodology has been properly used for different control problems [13-15]. This study presents a numerical analysis to decrease the effect of earthquake vibrations on building model having Active Tuned Mass Damper (ATMD). To select suitable switching gain and sliding surface parameter is significant for system performance. The search for these parameters has been done by two different fitness functions with Multi Objective Genetic Algorithm (MOGA). High Order Sliding Mode Controller (HOSMC) tuned with MOGA is designed for a three storey building model with ATMD. The simulation results of uncontrolled and controlled model are compared.

\section{Building Model with ATMD}

The building model has three degree of freedom (Figure 1). ATMD has been placed on top floor of the building model. $m_{i}, k_{i}$ and $b_{i}(i=1,2,3)$ denote the mass, stiffness and damping values related to each storey of the building model and $\mathrm{m}_{4}, \mathrm{k}_{4}$ and $\mathrm{b}_{4}$ stand for the mass, stiffness and damping values of the ATMD respectively. $\mathrm{u}$ is the control signal generated by the HOSMC.

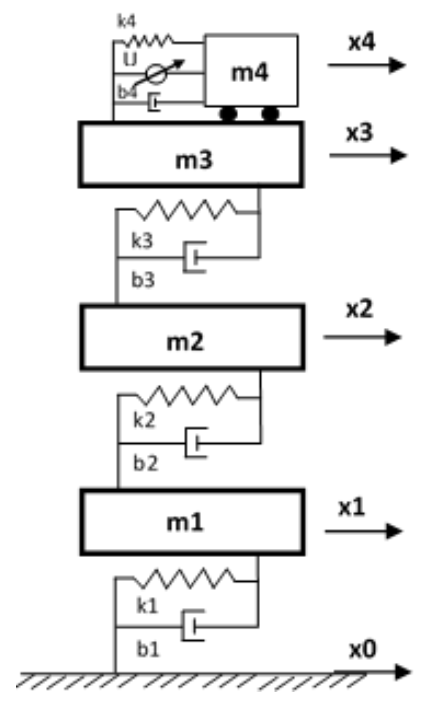

Figure 1. The psychical model of building model.

The mathematical model of the three-storey building model with ATMD has been obtained using Lagrange's equations and presented Eq. (1). The system has been excited by using recorded acceleration data of El-Centro earthquake.

$$
\begin{gathered}
{[M] \ddot{x}(t)+[B] \dot{x}(t)+[K] x(t)=P(t)} \\
x(t)=\left[\begin{array}{llll}
x_{1} & x_{2} & x_{3} & x_{4}
\end{array}\right]^{T}
\end{gathered}
$$

Mass, stiffness and damping matrix is shown in Eqs. (3-5).

$$
\begin{gathered}
{[M]=\operatorname{diag}\left[\begin{array}{llll}
m_{1} & m_{2} & m_{3} & m_{4}
\end{array}\right]} \\
{[B]=\left[\begin{array}{cccc}
b_{1}+b_{2} & -b_{2} & 0 & 0 \\
-b_{2} & b_{2}+b_{3} & -b_{3} & 0 \\
0 & -b_{3} & b_{3}+b_{4} & -b_{4} \\
0 & 0 & -b_{4} & b_{4}
\end{array}\right]} \\
{[K]=\left[\begin{array}{cccc}
k_{1}+k_{2} & -k_{2} & 0 & 0 \\
-k_{2} & k_{2}+k_{3} & -k_{3} & 0 \\
0 & -k_{3} & k_{3}+k_{4} & -k_{4} \\
0 & 0 & -k_{4} & k_{4}
\end{array}\right]}
\end{gathered}
$$


A linear motor is used as the control device. Linear motor force $F_{u}$, has been calculated using Eqs. (6) and (7) as shown in Eq. (8).

$$
\begin{gathered}
R i+K_{e}\left(\dot{x}_{4}-\dot{x}_{3}\right)=u \\
F_{u}=K_{f} i \\
F_{u}=\left(K_{f} / R\right) u-\left(K_{e} K_{f} / R\right)\left(\dot{x}_{4}-\dot{x}_{3}\right) \\
E_{\text {ATMD }}=F_{u}(t) \Delta x_{4}
\end{gathered}
$$

External loads have consisted of earthquake force and control force shown in Eq. (10).

$$
[P]=\left[\begin{array}{llll}
-m_{1} \ddot{x}_{0} & -m_{2} \ddot{x}_{0} & -m_{3} \ddot{x}_{0}-F_{u} & -m_{4} \ddot{x}_{0}+F_{u}
\end{array}\right]^{T}
$$

The mass and stiffness parameters of the building model have been taken from study of Sadek [7]. The damping parameters have been derived from $C=(0.0129) K[16]$ and the parameter of the ATMD has been shown Table 1-2.

Table 1. Ratios for building model (adapted from Sadek [7]).

\begin{tabular}{cccccc}
\hline $\begin{array}{c}\text { Number } \\
\text { of Floors }\end{array}$ & Mass ratio & $\begin{array}{c}\text { Tuning } \\
\text { Ratio (f) }\end{array}$ & $\begin{array}{c}\text { TMD damping } \\
\text { ratio }(\xi)\end{array}$ & $\begin{array}{c}M_{1}=\Phi_{1}^{T}[M] \Phi_{1} \\
\left(10^{3} \mathrm{~kg}\right)\end{array}$ & $\begin{array}{c}\omega_{01} \\
(\mathrm{~Hz})\end{array}$ \\
\hline 3 & 0.100 & 0.8701 & 0.3694 & 271 & 1.41 \\
\hline
\end{tabular}

Table 2. Parameters of building model with ATMD (adapted from Sadek [7]).

\begin{tabular}{cccc}
\hline Floor & Mass $\left(10^{3} \mathrm{~kg}\right)$ & Stiffness $(\mathrm{kN} / \mathrm{m})$ & $\begin{array}{c}\text { Damping } \\
\text { Coefficient }(\mathrm{kNs} / \mathrm{m})\end{array}$ \\
\hline 1 & 100 & 41000 & 528.9 \\
2 & 100 & 38000 & 490.2 \\
3 & 100 & 36000 & 464.4 \\
ATMD & 27.1 & 1610.73 & 154.35 \\
\hline
\end{tabular}

\section{Control Strategy}

\subsection{High Order Sliding Mode Controller Design with Super Twisting Algorithm}

Suppose that the system is defined as:

$$
\begin{gathered}
\dot{x}_{1}=x_{2} \\
\dot{x}_{2}=f\left(x_{1}, x_{2}\right)+g\left(x_{1}, x_{2}\right) \bar{u}+\bar{d}
\end{gathered}
$$

Here sliding surface is chosen as

$$
\sigma(x, t)=\alpha\left(x_{1 r}-x_{1}\right)+\left(\dot{x}_{1 r}-\dot{x}_{1}\right)
$$

Then by defining

$$
\begin{gathered}
\phi(x)=\alpha\left(x_{2 r}-x_{2}\right)+\dot{x}_{2 r}-f\left(x_{1}, x_{2}\right) \\
u=-g\left(x_{1}, x_{2}\right) \bar{u} \\
d=-\bar{d}
\end{gathered}
$$




$$
\begin{gathered}
\dot{\sigma}=\phi\left(x_{1}, x_{2}\right)+u+d \\
\left|\left(\phi\left(x_{1}, x_{2}\right)+d\right) / g\left(x_{1}, x_{2}\right)\right|<U_{M}
\end{gathered}
$$

If the control law is chosen to be [12]:

$$
\begin{gathered}
u=-k_{1}|\sigma|^{1 / 2} \operatorname{sign}(\sigma)+v \\
\dot{v}= \begin{cases}-u & |u|>U_{M} \\
-k_{2} \operatorname{sign}(\sigma) & |u| \leq U_{M}\end{cases}
\end{gathered}
$$

Suppose that $U_{M}$ is sufficiently large then the Lyapunov function can be selected as in [17]:

$$
\begin{gathered}
\xi^{T}=\left[|\sigma|^{1 / 2} \operatorname{sign}(\sigma)\right. \\
P=\frac{1}{2}\left[\begin{array}{cc}
4 k_{2}+k_{1}^{2} & -k_{1} \\
-k_{1} & 2
\end{array}\right] \\
V=\xi^{T} P \xi \\
V=2 k_{2}|\sigma|+\frac{1}{2} v^{2}+\frac{1}{2}\left(k_{1}|\sigma|^{1 / 2} \operatorname{sign}(\sigma)-v\right)^{2}
\end{gathered}
$$

It is assumed that the derivative of Lyapunov function with the bounded perturbation term is as in [17]:

$$
\begin{aligned}
& \dot{V}=-\frac{k_{1}}{2\left|\sigma^{1 / 2}\right|} \xi^{T} \tilde{Q} \xi \\
& \tilde{Q}=\left[\begin{array}{cc}
2 k_{2}+k_{1}^{2}-\left(\frac{4 k_{2}}{k_{1}}+k_{1}\right) \Delta & -k_{1}+\frac{\Delta}{2} \\
-k_{1}+\frac{\Delta}{2} & 1
\end{array}\right]
\end{aligned}
$$

It can be shown that by choosing $k_{1}>2 \Delta$ and $k_{2}>\Delta^{2} k_{1} /\left[8\left(k_{1}-2 \Delta\right)\right]$ then $\dot{V}<0$ then reaching to the sliding surface is guaranteed.

\subsection{Searching Optimum Controller Parameters using Multi-Objective Genetic Algorithm}

The proposed method can efficiently choose the appropriate gain parameters for high order sliding mode controller based on two proposed fitness functions. First fitness function is devised to obtain maximum reduction in the third floor response. The aim of the second fitness function is minimizing the control force and also minimizing third floor's response quantity. MOGA is implemented for tuning of the parameters of high order sliding mode controller. The obtain parameters of the controller have been shown Table 3 .

$$
\begin{gathered}
F F_{1}=\sum_{i=1}^{n}\left|x_{3 r i}-x_{3 i}\right| \\
F F_{2}=\sum_{i=1}^{n}\left|u_{i}\right|
\end{gathered}
$$


Table 3. Optimum Controller Parameters with MOGA.

\begin{tabular}{ccc}
\hline Controller & Parameter & Value \\
\hline \multirow{3}{*}{ HOSMC } & $\alpha$ & 4.75 \\
& $k_{1}$ & 7.01 \\
& $k_{2}$ & 0.66 \\
\hline
\end{tabular}

\subsection{Simulation Results}

Time responses are presented in Fig. 2-3. The building model has been excited by the recorded acceleration data of El-Centro earthquake that occurred in 1940. It is also seen that the displacement of the ATMD is also in reasonable ranges. From Fig. 2, it is observed that the best improvement in time response on floor 3 is obtained with designed HOSMCGA, since magnitudes for displacements in Fig. 2 are much more reduced if compared with the case without controller.
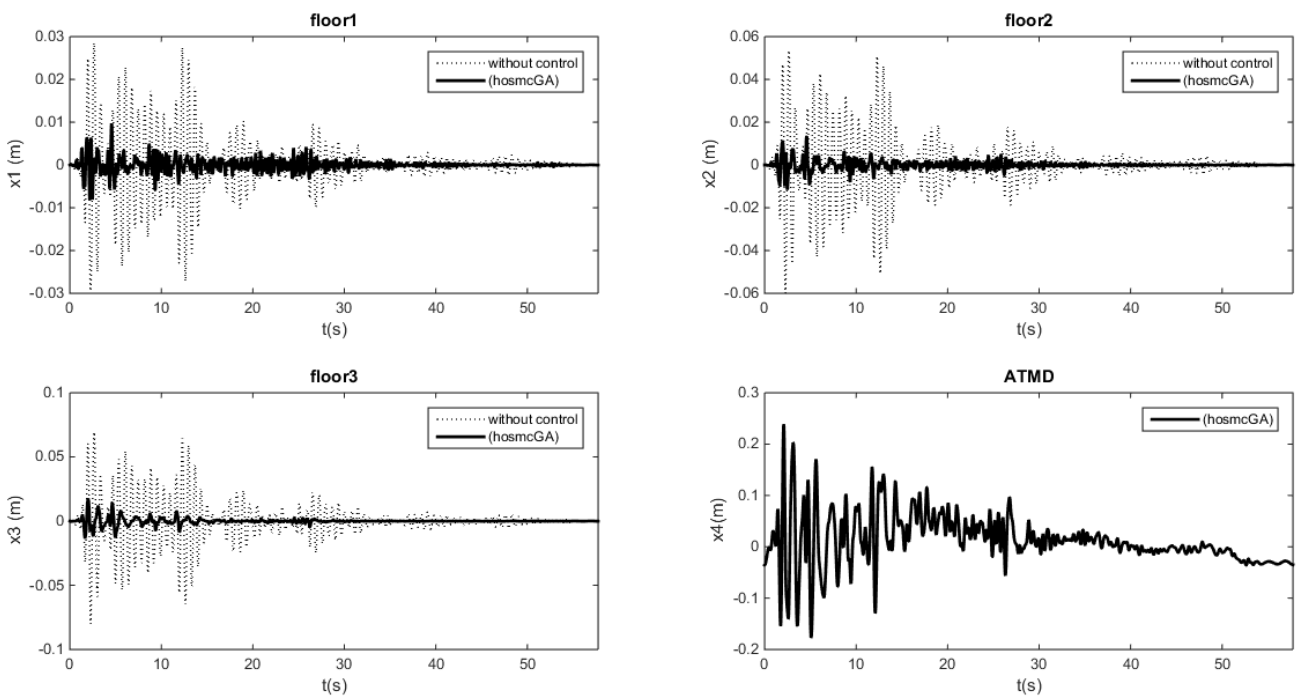

Figure 2. Displacements of floors and ATMD.

If Fig. 3 is investigated, it is seen that magnitude of accelerations are also reduced while the best reduction is obtained for floor 3 .
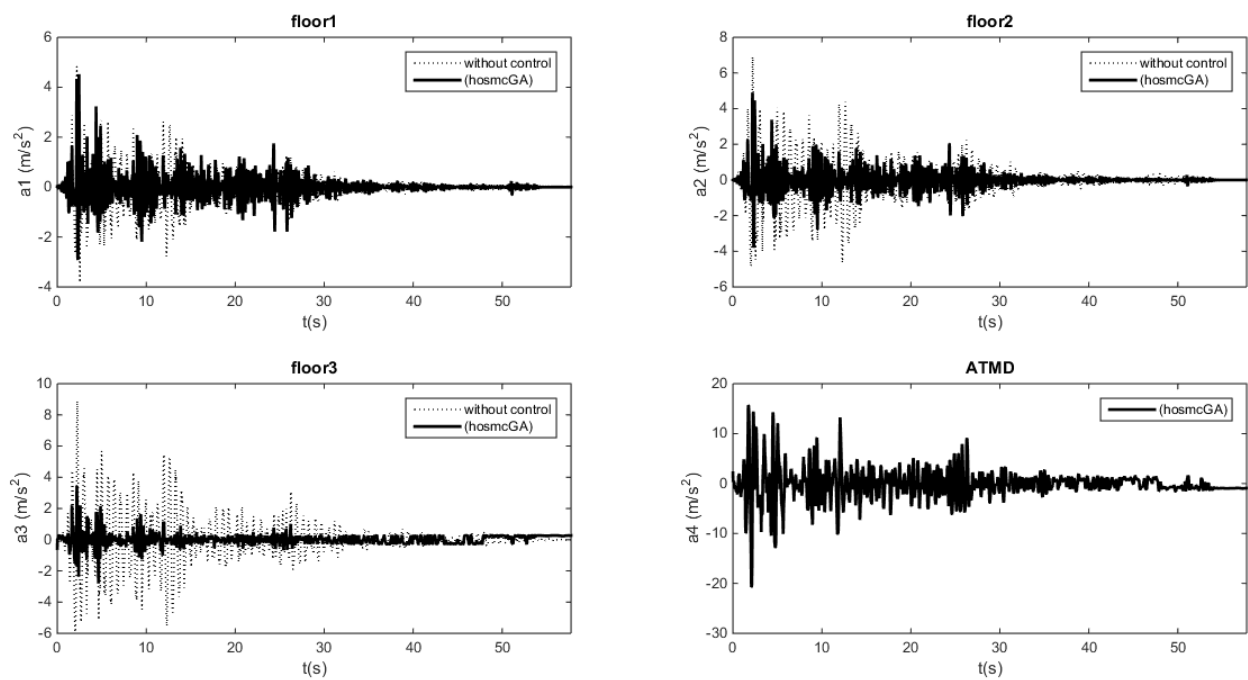

Figure 3. Accelerations of floors and ATMD.

The Root Mean Square (RMS) values for the displacements and accelerations of the building floors and ATMD are also calculated and presented in Table 4. It is deduced from those results that the designed HOSMCGA has decreased the RMS values substantially. 
Table 4. RMS values of all floors and ATMD.

\begin{tabular}{ccccccc}
\hline \multirow{2}{*}{ Floor } & \multicolumn{5}{c}{ RMS Values } \\
\cline { 2 - 6 } & Dithout & HOSMCGA & $\%$ & $\begin{array}{c}\text { Without } \\
\text { Controller }\end{array}$ & HOSMCGA & $\%$ \\
\hline & Controller & Hcceleration $(\mathrm{m} / \mathrm{s} 2)$ \\
\hline 1 & 0.00654 & 0.00139 & -78.7 & 0.6320 & 0.4700 & -25.6 \\
2 & 0.01230 & 0.00196 & -84.1 & 1.1100 & 0.5430 & -51.1 \\
3 & 0.01580 & 0.00232 & -85.3 & 1.4100 & 0.3400 & -75.9 \\
ATMD & - & 0.04960 & - & - & 2.9900 & - \\
\hline
\end{tabular}
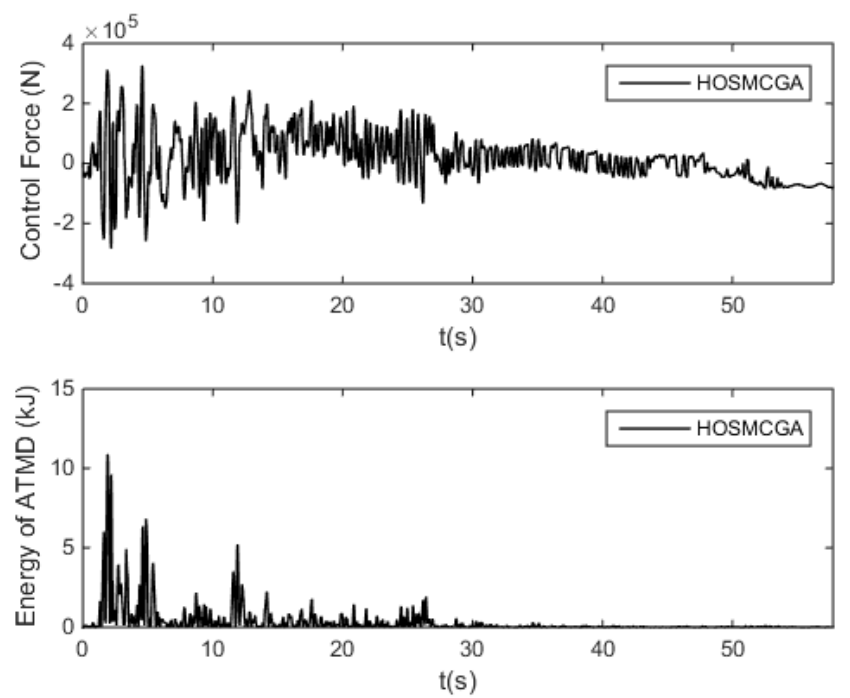

Figure 4. The time variation for the actuator force and energy consumption.

\section{Conclusions}

In this study, Active Tuned Mass Damper (ATMD) with high order sliding mode controller (HOSMC) tuned by Multi Objective Genetic Algorithm (MOGA) has been designed to reduce the vibrations of the three storey building model. The optimum values of HOSMC parameters $\left(\alpha, k_{1}, k_{2}\right)$ are obtained by MOGA. The RMS displacement value of third floor has been decreased by $85.3 \%$ if uncontrolled and controlled systems are compared. Similarly, the RMS acceleration value of third floor has been decreased by $75.9 \%$ if uncontrolled and controlled systems are compared. Finally, it can be concluded that the designed optimized HOSMCGA may perform well for the reduction of building vibrations.

\section{References}

[1] G.B. Warburton and E.O. Ayorinde, "Optimum Absorber Parameters for Simple Systems,"Earthquake Engineering \& Structural Dynamics, Vol. 3, pp. 197-217, 1980.

[2] G.B. Warburton, "Optimum Absorber Parameters for Various Combinations of Response and Excitation Parameters,"Earthquake Engineering \& Structural Dynamics, Vol. 3, pp. 381-401, 1982.

[3] A.G. Thompson, "Optimum Tuning and Damping of a Dynamic Vibration Absorber Applied to a Force Excited and Damped Primary System,"Journal of Sound and Vibration, Vol. 3, pp. 403-415, 1981.

[4] R. Villaverde, "Reduction in Seismic Response with Heavily-Damped Vibration Absorbers,"Earthquake Engineering \& Structural Dynamics, Vol. 1, pp. 33-42, 1985.

[5] R. Villaverde and L.A. Koyama, "Damped Resonant Appendages to Increase Inherent Damping in Buildings,"Earthquake Engineering \& Structural Dynamics, Vol. 6, pp. 491-507, 1993.

[6] R. Villaverde and S.C. Martin, "Passive Seismic Control of Cable-Stayed Bridges with Damped Resonant Appendages," Earthquake Engineering \& Structural Dynamics, Vol. 2, pp. 233-246, 1995. 
[7] F. Sadek, et al., "A method of estimating the parameters of tuned mass dampers for seismic applications,"Earthquake Engineering \& Structural Dynamics, Vol. 6, pp. 617-635, 1997.

[8] S. Pourzeynali, H.H. Lavasani, and A.H. Modarayi, "Active control of high rise building structures using fuzzy logic and genetic algorithms,"Engineering Structures, Vol. 3, pp. 346-357, 2007.

[9] V.I. Utkin, "Variable structure systems with sliding modes,"IEEE Transactions on Automatic control, Vol. 2, pp. 212-222, 1977.

[10] C. Edwards and S. Spurgeon, Sliding Mode Control: Theory and Applications. Taylor \& Francis Ltd. 1998.

[11] G. Bartolini, A. Ferrara, and E. Usai, "Chattering avoidance by second-order sliding mode control,"IEEE Transactions on Automatic Control, Vol. 2, pp. 241-246, 1998.

[12] A. Levant, "Sliding Order and Sliding Accuracy in Sliding Mode Control,"International Journal of Control, Vol. 6, pp. 1247-1263, 1993.

[13] A. Levant, "Homogeneity approach to high-order sliding mode design,"Automatica, Vol. 5, pp. 823830, 2005.

[14] A. Levant, "Principles of 2-sliding mode design,"Automatica, Vol. 4, pp. 576-586, 2007.

[15] H.O. Ozer, Y. Hacioglu, and N. Yagiz, "High order sliding mode control with estimation for vehicle active suspensions,"Transactions of the Institute of Measurement and Control, Doi: 10.1177/0142331216685394.

[16] R.W. Clough and J. Penzien, Dynamics of structures. McGraw-Hill. 1975.

[17] J.A. Moreno and M. Osorio, "A Lyapunov approach to second-order sliding mode controllers and observers,"47th IEEE Conference on Decision and Control, 2008 (CDC 2008), Vol., pp. 2856-2861, 2008. 